\title{
Risk Reduction Practices in Men Who Have Sex with Men in Switzerland: Serosorting, Strategic Positioning, and Withdrawal Before Ejaculation
}

\author{
Françoise Dubois-Arber • André Jeannin • \\ Stéphanie Lociciro $\cdot$ Hugues Balthasar
}

Received: 29 September 2010/Revised: 2 July 2011 / Accepted: 17 September 2011 / Published online: 15 November 2011

(C) Springer Science+Business Media, LLC 2011

\begin{abstract}
The aim of this study was to identify predictors of intentional use of the HIV risk reduction practices of serosorting, strategic positioning, and withdrawal before ejaculation during unprotected anal intercourse (UAI) with casual partners. A crosssectional survey pertaining to the Swiss HIV behavioral surveillance system, using an anonymous self-administered questionnaire, was conducted in 2007 in a self-selected sample of men having sex with other men (MSM). Analysis was restricted to participants with UAI with casual partner(s) $(N=410)$. Logistic regression was used to estimate factors associated with intentional use of serosorting, strategic positioning, and withdrawal before ejaculation. In the previous 12 months, $71 \%$ of participants reported having UAI with a casual partner of different or unknown HIVstatus. Of these, $47 \%$ reported practicing withdrawal, $38 \%$ serosorting, and $25 \%$ strategic positioning. In the 319 participants with known HIV-status, serosorting was associated with frequent Internet use to find partners ( $\mathrm{OR}=2.32)$, STI $(\mathrm{OR}=2.07)$, and HIV testing in the past 12 months $(\mathrm{OR}=1.81)$. Strategic positioning was associated with HIV-status $(\mathrm{OR}=0.13)$ and having UAI with a partner of different or unknown HIV-status $(\mathrm{OR}=3.57)$. Withdrawal was more frequently practiced by HIV-negative participants or participants reporting high numbers of sexual partners $(\mathrm{OR}=2.48)$ and having UAI with a partner of unknown or different serostatus $(\mathrm{OR}=2.08)$. Risk reduction practices are widely used by MSM, each practice having its own specificities. Further research is needed to
\end{abstract}

F. Dubois-Arber $(\bowtie) \cdot$ A. Jeannin $\cdot$ S. Lociciro

Institute of Social and Preventive Medicine, University Hospital

Center and University of Lausanne, Bugnon 17,

1005 Lausanne, Switzerland

e-mail: Francoise.Dubois-Arber@chuv.ch

H. Balthasar

Commission externe d'évaluation des politiques publiques,

Etat de Genève, Genève, Switzerland determine the contextual factors surrounding harm reduction practices, particularly the strategic or opportunistic nature of their use.

Keywords Risk reduction · HIV prevention · MSM . Sexual behavior

\section{Introduction}

In recent years (2000-2008), many European countries faced a noticeable resurgence in new cases of HIV and STI reported in men who have sex with men (MSM) (European Centre for Dis ease Prevention and Control, 2009; Hamers \& Downs, 2004). This was associated with an increase in anal penetration practices (Balthasar, Jeannin, \& Dubois-Arber, 2007; Van de Ven et al., 2004; Velter, Bouyssou-Michel, de Busscher, Jauffret-Roustide, \& Semaille, 2007) and a decrease in condom use (Balthasar et al., 2007; Bezemer et al., 2008; Bochow, Wright, \& Lange, 2004; Elford, 2006; Van de Ven et al., 2004; Van Kesteren, Hospers, \& Kok, 2007). As test uptake also increased in some countries, it has been debated if it is a true increase in incidence (Hart \& Elford, 2010); however, it is agreed, that at least incidence did not decrease.

Over the last 10 years, there was increasing evidence that MSM were likely to adopt protective behaviors alternative to condom use to reduce HIV transmission risk while having unprotected anal intercourse (UAI) (Elford, 2006; Van de Ven et al., 2004). These practices, generically labelled as "risk reduction behaviors," include practices such as "serosorting" (choosing to have unprotected sex with partners of same HIV-status), "strategic positioning" (the HIV-negative partner acts only as the insertive participant during the sex act and the HIV-positive partner acts only as the receptive participant), and withdrawal before ejaculation. Per-contact risk estimations were provided 
for these practices and none achieves a level of protection equivalent to condom use (Gold \& Skinner, 2001; Vittinghoff et al., 1999). However, a recent prospective cohort study showed that these practices were likely to reduce rates of HIV infection, with strategic positioning appearing to be the most effective practice followed by serosorting and withdrawal (Jin et al., 2009). It is probable that these practices do not decrease the transmission rate of other STI in the same proportion although no estimate is available.

Evidence of serosorting is reported in many places (Berry, Raymond, Kellogg, \& McFarland, 2008; Eaton et al., 2007; Golden, Stekler, Hughes, \& Wood, 2008; Halkitis, Moeller, \& Pollock, 2008; Parsons et al., 2005; Snowden, Raymond, \& McFarland, 2009; Truong et al., 2006; Van Kesteren et al., 2007; Velter, Bouyssou-Michel, Arnaud, \& Semaille, 2009) and appears to be on the increase in MSM (Golden et al., 2008; Mao et al., 2006; Velter et al., 2007). In particular, serosorting has been identified as an alternative practice adopted early after seroconversion among HIV positive individuals (Steward et al., 2009). Limitations in the use of serosorting have been demonstrated (Eaton, Kalichman, O'Connell, \& Karchner, 2009) and it has been argued that serosorting could potentially increase HIV transmission to the extent that rates of unrecognized and/or acute infection are high in the reference population (Pinkerton, 2008; Vittinghoff \& Padian, 1996). Recent research, including mathematical modelling, confirms these findings in settings where the percentage of undiagnosed infections is high but also suggests that serosorting may lead to effective risk reduction in settings with low proportions of undiagnosed infections; hence, testing frequency becomes an issue in high risk populations (Wilson et al., 2010).

Strategic positioning is used by MSM when having unprotected anal sex in the context of serodiscordant relationships and with casual partners by HIV positive MSM who report a higher prevalence of receptive UAI than insertive UAI with HIV seronegative partners or partners of uncertain status, thus supporting the hypothesis that this practice is intentional (Crepaz et al., 2009; Parsons et al., 2005; Van de Ven et al., 2002).

Withdrawal before ejaculation during anal sex may be well accepted in MSM as a harm reduction practice (Gold \& Skinner, 1997), although we know that pre-ejaculatory fluid may not be free of the virus (Ilaria et al., 1992; Pudney, Oneta, Mayer, Seage, $\&$ Anderson, 1992). High prevalences of withdrawal were reported in the United States, Australia, France, and Switzerland (Balthasar, Jeannin, \& Dubois-Arber, 2005; Parsons et al., 2005; Richters, Knox, Crawford, \& Kippax, 2000; Van de Ven et al., 2002; Velter et al., 2007).

In Switzerland, a general decrease in condom use-in particular with casual partners-has been observed over the last 10 years (Balthasar et al., 2007); consequently, new questions on risk reduction practices in this situation were introduced in 2007 in the national MSM survey regularly repeated as part of the behavioral surveillance system (Dubois-Arber, Jeannin, \& Meystre-
Agustoni, 2006). These questions deal with the intentional use of the above mentioned risk reduction practices to avoid HIV transmission, and were meant to assess the prevalence and characteristics of MSM using them as a means of risk management.

In a previous article, we analyzed the importance of risk reduction practices in the context of the overall protection strategy adopted by MSM having anal intercourse with their casual partners and factors associated with different levels of protection: systematic use of condoms, intentional use of risk reduction practices, and inconsistent condom use without any intentional use of risk reduction practices (Balthasar, Jeannin, Lociciro, \& Dubois-Arber, 2010). Findings suggested that risk reduction-all practices together-might be more an opportunistic response rather than a strategy per se. However, risk reduction practices-serosorting, strategic positioning, and withdrawal before ejaculation-were not examined separately.

In this article, we further explored the intentional use of risk reduction practices with casual partners as a way of avoiding HIV transmission and identify the specificities linked with each of these practices by analyzing demographic, lifestyle, and health-related factors associated with them, in order to better understand the profile of those who use them.

\section{Method}

\section{Participants}

Data were collected in 2007 in the context of an HIV behavioral surveillance survey (Gaysurvey; $N=2953$ ), which is part of the Swiss HIV behavioral surveillance system (Dubois-Arber et al., 2006; Dubois-Arber, Jeannin, \& Spencer, 1999). The survey has been repeated eight times between 1987 and 2007 (Balthasar et al., 2007; Balthasar, Jeannin, \& Dubois-Arber, 2008). The survey was cross-sectional, relied on a self-selected sample of MSM, and used an anonymous, self-administered questionnaire. The items on sexual risk reduction practices were introduced for the first time in the 2007 core questionnaire.

\section{Procedure}

The questionnaire had both a paper-and-pencil and an Internet mode of administration. The questionnaire was distributed through out the country through several channels, with the assistance of gay organizations: a paper-and-pencil questionnaire was inserted in the main gay newspapers published in Switzerland, mailed by almost all gay organizations to their members, and distributed in gay bathhouses. The questionnaire was also available on the internet; the online version was announced with banners published on the main gay websites within the Switzerland Internet domain (".ch"). More details on the dissemination of the questionnaire have been published elsewhere (Balthasar et al., 2007; Balthasar, Jeannin, \& Dubois-Arber, 2009; Balthasar 
et al., 2010). The data were collected between June and October 2007.

The questionnaire was reviewed by the Swiss Federal Office of Public Health, the Swiss AIDS Foundation, and gay community leaders. The survey was approved by the ethical review board of the Faculty of Medicine and Biology at Lausanne University, Switzerland.

\section{Measures}

The questionnaire has been used in its current form for most items since 1992, for behavioral surveillance purposes. The main indicators that were used for surveillance were agreed upon at the European level. It provided information on sociodemographic characteristics, number of sexual partners (all types of partners) in the past 12 months, HIV-status (self-reported), STI history, and preventive behaviors in the last 12 months in different relationship contexts (casual/steady partners and partners with different or unknown HIV-status).

The use of sexual risk reduction practices was assessed with three questions which were new questions (one per practice), each referring to unprotected anal intercourse with casual partners and stressing the participant's purposeful decision to reduce HIV transmission risks in such circumstances: (1) Serosorting: "Over the past 12 months, did you ever practice anal penetration without a condom, having previously asked your partner if he was of the same HIV-status as you, in order to avoid HIV infection? (with casual partners: yes/no)"; (2) Strategic positioning: "Over the past 12 months, did you ever practice anal penetration without a condom and choose only the insertive or receptive role in order to avoid HIV infection? (with casual partners: yes, only receptive/yes, only active/no)"; (3) Withdrawal before ejaculation: "Over the past 12 months, did you ever practice anal penetration without a condom and withdraw before ejaculation in order to avoid HIV infection? (with casual partners: yes/no)."

A casual partner was defined in the questionnaire as any sexual partner that the participant did not consider to be his steady partner. The label for each practice did not appear in the questionnaire.

\section{Data Analysis}

In the first step, the analyses were restricted to the participants who reported having had UAI with at least one casual partner in the past 12 months $(n=410 ; 13.8 \%)$. The prevalence of each practice was evaluated.

In the second step, participants of unknown HIV-status (refused to answer or didn't know, $n=18$, and non-tested participants, $n=73$ ) were excluded from the analyses on serosorting and strategic positioning since these practices require an a priori knowledge of this information. However, these 91 individuals were retained in the analysis of withdrawal.

Univariate and independent multivariate logistic regressions were performed to identify predictors of each HIV risk reduction practice. The following variables were used as predictors:

\section{Sociodemographics Characteristics}

The variables included in the analysis were: age $(<25$ years, 25-34 years, or $\geq 35$ years), nationality, size of the city of residence (above/below 100,000 inhabitants), education level (university degree vs. less than university degree).

\section{Relational Status}

The relational status was defined by the variable "having had a steady relationship with a male partner during the past 12 months" (yes/no).

\section{Sexual Activity}

Sexual activity was defined by the number of sexual partners (all types of partners) with whom anal penetration had been practiced in the past 12 months.

\section{Contexts Possibly Associated with Decisions on Harm Reduction (Past 12 Months)}

Two variables were used to take into account such contexts: regularly visiting sex-on-premises venues, and regularly seeking sexual partners through the Internet.

\section{Prevention and Risk Reduction}

The two following variables: having visited a prevention website of the Swiss AIDS Foundation containing information on harm reduction practices (past 12 months), and being member in a gay organization were used as proxies for MSM related information.

\section{Risks}

Three variables were used in the analysis: having had any STI (past 12 months), UAI with a partner of different or unknown HIV-status (past 12 months), and frequent use of substances while having sex (past 12 months).

\section{HIV Test}

We used two variables: having been tested recently (past 12 months), and reported HIV-status. 


\section{Survey Mode}

The survey mode identified paper versus online questionnaire.

\section{Dependent Variable}

Each of the three practices (serosorting, strategic positioning and withdrawal) was used as the dependent variable.

We also compared the profiles of those reporting $0,1,2$ or 3 practices, using the same variables as in the regression. We used bivariate analysis with Pearson's $\chi^{2}$; individual tests were assessed at $\alpha \leq .003$ with Bonferroni correction, yielding an overall $\alpha$ level of .05 . Data were analyzed using the statistical package STATA 10.0.

\section{Results}

\section{Demographics}

Of the 410 participants having had UAI with at least one casual partner in the past 12 months, 261 (64\%) completed the questionnaire online. Sociodemographic and behavioral characteristics differed strongly according to the survey mode. Internet participants were younger than those who completed the paper questionnaire and less likely to report a higher education degree or live in a city of more than 100,000 inhabitants.

\section{Risk Reduction Practices}

Overall, $71 \%$ of the 410 participants who had UAI with at least one casual partner in the past 12 months reported having had UAI with a partner of different or unknown HIV-status in the past 12 months (33\% one time; $38 \%$ several times). About $80 \%$ of participants were ever tested for HIV and $43 \%$ had an HIV test in the past 12 months. In comparison with the entire Gaysurvey sample, our selected participants reported more sexual partners (median of 5 vs. 3 ) and the proportion of HIV-positive participants in this study was $21 \%$ compared with $12 \%$ and $6 \%$ for the paper and Internet questionnaires, respectively, in the whole survey (Balthasar et al., 2008).

The first step of the analysis, which included all 410 participants who had UAI with casual partners (HIV-negative, HIVpositive, and non-tested), provided information with which to obtain the proportion of participants using each harm reduction practice. Of the 410 participants selected, $38 \%$ had practiced serosorting in the past 12 months and $25 \%$ practiced strategic positioning. About half of participants (47\%) reported practicing withdrawal before ejaculation. Seventy-one percent of participants used at least one of the three practices, $37 \%$ reported only one practice, $29 \%$ reported two practices, and $5 \%$ reported three. Twenty-nine percent did not use any risk reduction practice.
Differences were observed according to the HIV-status of the participants (Table 1). Among HIV-negative and non-tested participants, withdrawal was the most frequently reported practice ( $52.6 \%$ and $38.4 \%$, respectively), while HIV-positive participants reported serosorting most frequently $(40.9 \%$, as much as their HIV-negative counterparts) and withdrawal second most frequently $(33.3 \%)$. Regarding strategic positioning, the discrepancy according to HIV-status was particularly high, with $26.9 \%$ of HIV-negative participants reporting this practice compared with $7.6 \%$ of HIV-positive participants. Among the non-tested participants, $30.1 \%$ practiced strategic positioning, i.e. by choosing to be the insertive partner only.

The second step of the analysis was restricted to observations about participants who reported having been tested for HIV $(n=319)$. Univariate and multivariate analyzes were used to identify details and investigate the profile of these participants according to their practices.

\section{Serosorting}

The univariate analysis (Table 2) showed associations between serosorting and several variables, such as regularly frequenting sex-on-premises venues ( $p=.002)$, frequent use of the Internet to find sexual partners ( $p=.004)$, having contracted a STI in the past 12 months ( $p=.040)$, and having had UAI with partners of different or unknown HIV-status $(p<.001)$.

The logistic regression (Table 3 ) confirmed these associations and, in addition, highlighted the use of HIV testing in the past 12 months as another significant covariate of serosorting. Odds ratios (OR) greater than one were found between serosorting and frequent use of the Internet $(\mathrm{OR}=2.32), \mathrm{STI}(\mathrm{OR}=2.07)$ and HIV testing in the past 12 months $(\mathrm{OR}=1.81)$, whereas ORs less than one were found for regularly frequenting sex-onpremises venues $(\mathrm{OR}=0.39)$ and UAI with partners of different or unknown HIV-status $(\mathrm{OR}=0.14)$.

\section{Strategic Positioning}

According to the univariate analysis (Table 2), strategic positioning was associated with the age of the participant $(p=.034)$, regularly frequenting sex-on-premises venues $(p=.043)$, UAI with partners of different or unknown HIV-status $(p=.003)$, and HIV-status $(p=.001)$.

In the logistic regression (Table 3), two factors remained associated with strategic positioning: UAI with a partner of different HIV-status $(\mathrm{OR}=3.57)$ and HIV-status, with HIV-positive participants being less likely to practice strategic positioning $(\mathrm{OR}=0.13)$.

Withdrawal

The profile of participants who reported practicing withdrawal before ejaculation was similar to that of participants practicing 
Table 1 Risk reduction practices according to the HIV-status of the respondent ${ }^{\mathrm{a}}$

\begin{tabular}{|c|c|c|c|c|c|c|c|}
\hline \multirow[t]{2}{*}{ HIV-status } & & \multicolumn{2}{|c|}{ Serosorting } & \multicolumn{2}{|c|}{ Strategic positioning } & \multicolumn{2}{|c|}{ Withdrawal } \\
\hline & & Yes & No & Yes & No & Yes & No \\
\hline \multirow[t]{2}{*}{ HIV-negative } & $N$ & 106 & 147 & 68 & 185 & 133 & 120 \\
\hline & $\%$ & 41.9 & 58.1 & 26.9 & 73.1 & 52.6 & 47.4 \\
\hline \multirow[t]{2}{*}{ HIV-positive } & $N$ & 27 & 39 & 5 & 61 & 22 & 44 \\
\hline & $\%$ & 40.9 & 59.1 & 7.6 & 92.4 & 33.3 & 66.7 \\
\hline \multirow[t]{2}{*}{ Non-tested } & $N$ & 14 & 59 & 22 & 51 & 28 & 45 \\
\hline & $\%$ & 19.2 & 80.8 & 30.1 & 69.9 & 38.4 & 61.6 \\
\hline \multirow[t]{2}{*}{ Refused to answer/did not know } & $N$ & 7 & 11 & 7 & 11 & 9 & 9 \\
\hline & $\%$ & 38.9 & 61.1 & 38.9 & 61.1 & 50.0 & 50.0 \\
\hline
\end{tabular}

${ }^{a}$ Based on participants who reported having had unprotected anal intercourse with at least one casual partner in the past 12 months

strategic positioning. In the univariate analysis (Table 2), associations between withdrawal and age 25 and older $(p=$ .009), high number of sexual partners (more than six) $(p=$ .006), UAI with a partner of unknown or different HIV-status $(p=.001)$, and HIV-status $(p=.008)$ were observed. As was the case for strategic positioning, HIV-positive participants were less likely to practice withdrawal before ejaculation as a form of risk reduction strategy.

The logistic regression confirmed these associations (Table 3). Results showed that withdrawal was more frequently practiced by HIV-negative participants, participants who reported a high number of sexual partners $(\mathrm{OR}=2.48)$, and by those who reported UAI with a partner of unknown or different serostatus $(\mathrm{OR}=$ 2.08).

Lastly, we compared those reporting $0,1,2$ or the three practices and did not find significant differences in their profile (data not shown).

\section{Discussion}

This study estimated the intentional use HIV risk reduction practices in MSM who reported having UAI with casual sexual partners. The study found that about $75 \%$ of MSM tried to reduce the risk of HIV infection while having unprotected sex by using withdrawal before ejaculation, serosorting or strategic positioning, ranked here in their order of prevalence. This study also compared the characteristics associated with each of these practices and found specificities linked with the use of each of them.

Risk reduction practices were highly prevalent among MSM who reported UAI with casual partners and a significant proportion of MSM used more than one of these practices. This finding is interesting, since such practices were never promoted in Switzerland by either public health authorities or HIV prevention or gay organizations, suggesting that individual HIV risk management has increased among MSM over the past several years. The results suggest that MSM are likely to consider or use alternative prevention practices, even if these practices have questionable efficacy. However, we could ascertain the extent to which the study participants used these as strategies,i.e., whether they used these practices consistently as an alternative to condom use or whether they adopted these practices "in the heat of the moment" for different contextual reasons, such as substance consumption, familiarity with the partner, emotional state, etc. As some of these practices convey a certain amount of risk, data on frequency of utilisation of these would be useful as would be more qualitative data to distinguish the use of these practices as a rescue in given situations or as a conscious strategy.

Risk reduction practices are often associated with positive HIV-status (Jin et al., 2009; Suarez et al., 2001; Wolitski, Parsons, \& Gomez, 2004). In a recent review (Van Kesteren et al., 2007), it was shown that HIV-positive MSM were more likely to engage in UAI with other HIV-positive MSM than with those who were HIV-negative, in both primary and non-primary relationships. However, in line with results from France (Velter et al., 2007) and Australia (Mao et al., 2006), our data showed that risk reduction practices were not limited to HIV-positive MSM. We observed that, indeed, both HIV-negative and, surprisingly, non-tested participants also used these three practices.

Several hypotheses can be proposed to explain the results concerning the non-tested participants; these are that an error was made by the participants when they completed the questionnaire, a data entry error occurred, or, very likely, these participants have a subjective certainty concerning their own status and act accordingly.

As expected, the comparison between HIV-negative and HIV-positive MSM showed behavioral differences concerning the practices chosen. Among MSM who had UAI with casual partners, HIV-positive participants tended to report more serosorting whereas HIV-negative participants reported more frequently withdrawal before ejaculation. Strategic positioning is the least practiced in order of reporting, regardless of HIV-status. The most frequently used practice by the participants, withdrawal before ejaculation, is of great concern because this practice was shown to be the least effective (Jin et al., 2009). Per contact 
Table 2 Associations between risk reduction practices and demographic and behavioral characteristics

\begin{tabular}{|c|c|c|c|c|c|c|c|c|c|}
\hline & \multicolumn{3}{|c|}{ Serosorting $(N=319)$} & \multicolumn{3}{|c|}{ Strategic positioning $(N=319)$} & \multicolumn{3}{|c|}{ Withdrawal $(N=410)$} \\
\hline & $n$ & $\%$ & $p$ & $n$ & $\%$ & $p$ & $n$ & $\%$ & $p$ \\
\hline \multicolumn{10}{|l|}{ Age } \\
\hline$<25$ years & 21 & 40.4 & & 5 & 9.62 & & 26 & 31.7 & \\
\hline $25-34$ years & 45 & 48.9 & & 21 & 22.8 & & 61 & 50.4 & \\
\hline 35 years and more & 67 & 38.3 & ns & 47 & 26.9 & .034 & 105 & 50.7 & .009 \\
\hline \multicolumn{10}{|l|}{ Nationality } \\
\hline Swiss national & 109 & 40.7 & & 66 & 24.6 & & 157 & 46.0 & \\
\hline Non-Swiss national & 24 & 47.1 & ns & 7 & 13.7 & .089 & 184 & 54.0 & ns \\
\hline \multicolumn{10}{|c|}{ Residence area $>100,000$ inhabitants } \\
\hline No & 72 & 41.4 & & 38 & 21.8 & & 106 & 44.5 & \\
\hline Yes & 61 & 42.1 & ns & 35 & 24.1 & ns & 86 & 50.0 & ns \\
\hline \multicolumn{10}{|l|}{ University degree } \\
\hline No & 67 & 40.4 & & 37 & 22.3 & & 101 & 44.7 & \\
\hline Yes & 66 & 43.1 & $\mathrm{~ns}$ & 36 & 23.5 & $\mathrm{~ns}$ & 91 & 49.5 & $\mathrm{~ns}$ \\
\hline \multicolumn{10}{|l|}{ Steady partner ${ }^{\mathrm{a}}$} \\
\hline No & 102 & 41.3 & & 52 & 21.1 & & 146 & 45.2 & \\
\hline Yes & 31 & 43.1 & ns & 21 & 29.2 & $\mathrm{~ns}$ & 46 & 52.9 & ns \\
\hline \multicolumn{10}{|l|}{ Sexual partners ${ }^{\mathrm{a}, \mathrm{b}}$} \\
\hline $1-5$ partners & 59 & 39.3 & & 36 & 24.0 & & 83 & 40.1 & \\
\hline 6 or more partners & 74 & 43.8 & ns & 37 & 21.9 & ns & 109 & 53.7 & .006 \\
\hline \multicolumn{10}{|c|}{ Regularly frequenting sex-on-premises venues ${ }^{\mathrm{a}}$} \\
\hline No & 117 & 46.1 & & 52 & 20.5 & & 151 & 45.9 & \\
\hline Yes & 16 & 24.6 & .002 & 21 & 32.3 & 043 & 41 & 50.6 & $\mathrm{~ns}$ \\
\hline \multicolumn{10}{|c|}{ Frequent use of Internet for sexual encounters ${ }^{\mathrm{a}}$} \\
\hline No & 63 & 34.8 & & 42 & 23.2 & & 110 & 46.6 & \\
\hline Yes & 70 & 50.7 & .004 & 31 & 22.5 & ns & 82 & 47.1 & ns \\
\hline \multicolumn{10}{|c|}{ Ever visited website on RRP } \\
\hline No & 115 & 40.2 & & 68 & 23.8 & & 18 & 42.9 & \\
\hline Yes & 18 & 54.6 & ns & 5 & 15.2 & ns & 174 & 47.3 & ns \\
\hline \multicolumn{10}{|l|}{ Gay organization } \\
\hline No & 107 & 39.9 & & 63 & 23.5 & & 158 & 45.0 & \\
\hline Yes & 26 & 51.0 & ns & 10 & 19.6 & ns & 34 & 57.6 & .072 \\
\hline \multicolumn{10}{|l|}{$\mathrm{STI}^{\mathrm{a}}$} \\
\hline No & 100 & 38.9 & & 60 & 23.4 & & 160 & 47.1 & \\
\hline Yes & 33 & 53.2 & .004 & 13 & 21.0 & $\mathrm{~ns}$ & 32 & 45.7 & $\mathrm{~ns}$ \\
\hline \multicolumn{10}{|c|}{$\begin{array}{l}\text { UAI with partners of different or } \\
\text { unknown HIV-status }{ }^{\mathrm{a}}\end{array}$} \\
\hline No & 61 & 69.3 & & 10 & 11.4 & & 40 & 33.9 & \\
\hline Yes & 72 & 31.2 & ns & 63 & 27.3 & .003 & 152 & 52.1 & .001 \\
\hline \multicolumn{10}{|c|}{ Frequent substance use while having se ${ }^{a}$} \\
\hline No & 105 & 41.02 & & 63 & 24.61 & & 161 & 48.35 & \\
\hline Yes & 28 & 44.44 & ns & 10 & 15.87 & ns & 31 & 40.26 & ns \\
\hline \multicolumn{10}{|l|}{ HIV-test ${ }^{\mathrm{a}}$} \\
\hline No & 53 & 36.1 & & 36 & 24.5 & & 108 & 46.0 & \\
\hline Yes & 80 & 46.5 & .059 & 37 & 21.5 & $\mathrm{~ns}$ & 84 & 48.0 & $\mathrm{~ns}$ \\
\hline \multicolumn{10}{|l|}{ HIV-status } \\
\hline Unknown & $\mathrm{NI}$ & NI & & NI & $\mathrm{NI}$ & & 37 & 40.7 & \\
\hline HIV negative & 106 & 41.9 & & 68 & 26.9 & & 133 & 52.6 & \\
\hline
\end{tabular}


Table 2 continued

\begin{tabular}{|c|c|c|c|c|c|c|c|c|c|}
\hline & \multicolumn{3}{|c|}{ Serosorting $(N=319)$} & \multicolumn{3}{|c|}{ Strategic positioning $(N=319)$} & \multicolumn{3}{|c|}{ Withdrawal $(N=410)$} \\
\hline & $n$ & $\%$ & $p$ & $n$ & $\%$ & $p$ & $\bar{n}$ & $\%$ & $p$ \\
\hline HIV positive & 27 & 40.9 & ns & 5 & 7.6 & .001 & 22 & 33.3 & .008 \\
\hline
\end{tabular}

$N I$ none included in analysis, $S T I$ sexually transmitted infections, $U A I$ unprotected anal intercourse, $R R P$ risk reduction practices

${ }^{a}$ In the past 12 months

b With anal intercourse

Table 3 Multivariate analyses ${ }^{\mathrm{a}}$

\begin{tabular}{|c|c|c|c|c|c|c|c|c|c|}
\hline & \multicolumn{3}{|c|}{ Serosorting $(N=319)$} & \multicolumn{3}{|c|}{ Strategic positioning $(N=319)$} & \multicolumn{3}{|c|}{ Withdrawal $(N=410)$} \\
\hline & Adj. OR & $95 \% \mathrm{CI}$ & $p$ & Adj. OR & $95 \% \mathrm{CI}$ & $p$ & Adj. OR & $95 \% \mathrm{CI}$ & $p$ \\
\hline \multicolumn{10}{|l|}{ Age } \\
\hline$<25$ years & 0.62 & $0.27 ; 1.41$ & ns & 0.40 & $0.13 ; 1.21$ & ns & 0.48 & $0.25 ; 0.93$ & .029 \\
\hline $25-34$ years & 1 & & & 1 & & & 1 & & \\
\hline 35 years and more & 0.71 & $0.38 ; 1.32$ & ns & 1.56 & $0.80 ; 3.02$ & ns & 1.06 & $0.64 ; 1.75$ & ns \\
\hline \multicolumn{10}{|l|}{ Nationality } \\
\hline Swiss national & 1 & & & 1 & & & 1 & & \\
\hline Non-Swiss national & 1.69 & $0.84 ; 3.40$ & ns & 0.48 & $0.19 ; 1.20$ & ns & 1.36 & $0.77 ; 2.41$ & ns \\
\hline \multicolumn{10}{|c|}{ Residence area $>100,000$ inhabitants } \\
\hline No & 1 & & & 1 & & & 1 & & \\
\hline Yes & 0.98 & $0.55 ; 1.74$ & $\mathrm{~ns}$ & 1.40 & $0.76 ; 2.59$ & ns & 1.18 & $0.75 ; 1.87$ & $\mathrm{~ns}$ \\
\hline \multicolumn{10}{|l|}{ University degree } \\
\hline No & 1 & & & 1 & & & 1 & & \\
\hline Yes & 1.13 & $0.65 ; 1.97$ & ns & 0.80 & $0.43 ; 1.46$ & ns & 0.84 & $0.53 ; 1.33$ & ns \\
\hline \multicolumn{10}{|l|}{ Steady partner ${ }^{\mathrm{b}}$} \\
\hline No & 1 & & & 1 & & & 1 & & \\
\hline Yes & 0.94 & $0.49 ; 1.82$ & ns & 1.85 & $0.91 ; 3.74$ & .087 & 1.39 & $0.81 ; 2.40$ & ns \\
\hline \multicolumn{10}{|l|}{ Sexual partners ${ }^{\mathrm{b}, \mathrm{c}}$} \\
\hline $1-5$ partners & 1 & & & 1 & & & 1 & & \\
\hline 6 or more partners & 1.51 & $0.82 ; 2.76$ & ns & 0.81 & $0.41 ; 1.60$ & ns & 2.48 & $1.51 ; 4.08$ & .001 \\
\hline \multicolumn{10}{|c|}{ Regularly frequenting sex-on-premises venues ${ }^{\mathrm{b}}$} \\
\hline No & 1 & & & 1 & & & 1 & & \\
\hline Yes & 0.39 & $0.19 ; 0.82$ & .013 & 1.81 & $0.86 ; 3.82$ & ns & 0.75 & $0.42 ; 1.33$ & ns \\
\hline \multicolumn{10}{|c|}{ Frequent use of Internet for sexual encounters ${ }^{b}$} \\
\hline No & 1 & & & 1 & & & 1 & & \\
\hline Yes & 2.32 & $1.32 ; 4.07$ & .003 & 1.09 & $0.58 ; 2.06$ & ns & 0.84 & $0.53 ; 1.32$ & ns \\
\hline \multicolumn{10}{|c|}{ Ever visited website on RRP } \\
\hline No & 1 & & & 1 & & & 1 & & \\
\hline Yes & 2.10 & $0.88 ; 5.00$ & .093 & 0.57 & $0.19 ; 1.73$ & ns & 0.90 & $0.43 ; 1.85$ & ns \\
\hline \multicolumn{10}{|l|}{ Gay organization } \\
\hline No & 1 & & & 1 & & & 1 & & \\
\hline Yes & 1.73 & $0.83 ; 3.60$ & ns & 0.98 & $0.42 ; 2.30$ & ns & 1.65 & $0.89 ; 3.07$ & $\mathrm{~ns}$ \\
\hline \multicolumn{10}{|l|}{$\mathrm{STI}^{\mathrm{b}}$} \\
\hline No & 1 & & & 1 & & & 1 & & \\
\hline Yes & 2.07 & $1.05 ; 4.07$ & .035 & 1.05 & $0.48 ; 2.31$ & ns & 0.93 & $0.52 ; 1.66$ & ns \\
\hline \multicolumn{10}{|c|}{ UAI with partners of different or unknown HIV-status ${ }^{b}$} \\
\hline No & 1 & & & 1 & & & 1 & & \\
\hline Yes & 0.14 & $0.07 ; 0.27$ & .001 & 3.57 & $1.60 ; 7.94$ & .002 & 2.08 & $1.27 ; 3.42$ & .004 \\
\hline
\end{tabular}


Table 3 continued

\begin{tabular}{|c|c|c|c|c|c|c|c|c|c|}
\hline & \multicolumn{3}{|c|}{ Serosorting $(N=319)$} & \multicolumn{3}{|c|}{ Strategic positioning $(N=319)$} & \multicolumn{3}{|c|}{ Withdrawal $(N=410)$} \\
\hline & Adj. OR & $95 \% \mathrm{CI}$ & $p$ & Adj. OR & $95 \% \mathrm{CI}$ & $p$ & Adj. OR & $95 \% \mathrm{CI}$ & $p$ \\
\hline \multicolumn{10}{|c|}{ Frequent substance use while having sex ${ }^{b}$} \\
\hline No & 1 & & & 1 & & & 1 & & \\
\hline Yes & 1.35 & $0.69 ; 2.64$ & ns & 0.47 & $0.21 ; 1.07$ & .072 & 0.57 & $0.33 ; 1.01$ & .053 \\
\hline \multicolumn{10}{|l|}{ HIV-test ${ }^{\mathrm{b}}$} \\
\hline No & 1 & & & 1 & & & 1 & & \\
\hline Yes & 1.81 & $1.05 ; 3.13$ & .033 & 0.61 & $0.33 ; 1.13$ & ns & 0.73 & $0.45 ; 1.19$ & ns \\
\hline \multicolumn{10}{|l|}{ HIV-status } \\
\hline Unknown & NI & & & NI & & & 0.63 & $0.35 ; 1.14$ & ns \\
\hline HIV negative & 1 & & & 1 & & & 1 & & \\
\hline HIV positive & 0.82 & $0.40 ; 1.68$ & ns & 0.13 & $0.04 ; 0.38$ & .001 & 0.26 & $0.13 ; 0.50$ & .001 \\
\hline
\end{tabular}

$N I$ not included in analysis, $S T I$ sexually transmitted infections, $U A I$ unprotected anal intercourse, $R R P$ risks reduction practices, $C I$ confidence interval, Adj. OR adjusted odds ratio

${ }^{\text {a }}$ Controlled for survey mode (paper versus online questionnaire)

b In the past 12 months

${ }^{c}$ With anal intercourse

risk of HIV transmission in case of receptive UAI with withdrawal has been estimated to be only about half the risk of UAI with ejaculation (Jin et al., 2010) and higher risks of STI have been shown to be associated with withdrawal among heterosexual adolescents (Sznitman et al., 2009). Difficulties to actually put in practice withdrawal were also illustrated by elevated contraceptive failures among women using this method (Trussell \& Vaughan, 1999).

Among the three practices evaluated in the study, serosorting was the only practice that could be identified as a "structured strategy." Reported by $42 \%$ of our participants, serosorting appeared to be practiced in a coherent and structured manner. First, it was significantly associated with the regular use of the Internet to find sexual partners, a tool that makes it considerably easier to select sexual partners according to a wide range of selection criteria, including HIV-status and adherence to safer sex guidelines. Second, serosorting was associated with recent HIV testing (past 6 months), which is theoretically a prerequisite to use this strategy. Third, we found that MSM who reported having had UAI with partners of different or unknown HIV-status were less likely to practice serosorting. All these independent associations suggest that serosorters may use this practice with casual partners in a coherent, strategic way. Lastly, our data showed a strong association between the use of serosorting and STI in the past 12 months. STI are more prevalent in HIV-positive persons and this may be one of the reasons. Our study design did not allow us to make such assumptions regarding withdrawal and strategic positioning, because additional contextual and qualitative information would be required.

Regarding strategic positioning, our data showed that this practice was most frequently reported by HIV-negative participants. In the overall sample, we observed that HIV-negative
MSM were more likely to choose to be the insertive participant during anal intercourse with casual partners regardless of their preventive strategy. We did not observe a similar trend among partners in a steady relationship (Balthasar et al., 2008). In addition, strategic positioning could be at odds with personal sexual preferences regarding sexual position.

None of these practises achieves the same level of efficacy regarding HIV transmission as condom use, especially in the context of casual relationships, and, when used specifically to reduce HIV risk, do not protect against other STIs. Moreover, any level of protection these practices may offer can be altered by contextual factors that are beyond the individual's control. The efficacy of serosorting, for example, depends highly on the prevalence of acute HIV infections (Butler \& Smith, 2007; Pinkerton, 2008), on the universality and frequency of HIV testing (Wilson et al., 2010), and on the accuracy and veracity of the information presumably shared by the sexual partners, particularly HIVstatus. Serosorting may increase HIV transmission when the prevalence of acute infections is high and the level of undiagnosed infections is low. The risk of HIV transmission is higher during the first phase of HIV infection, when HIV is most often undiagnosed.

We compared the profile of participants who used $0,1,2$ or 3 strategies and did not find significant differences. This may seem surprising as we found profile differences associated with each strategy. We do not know, however, the frequency with which each of the practice was used when several were mentioned. It is possible that participants have preferences regarding the type of harm reduction practice they use and may add one or two more to their repertoire according to the situation and partner encountered.

Our results have implications in terms of research and prevention. Regarding research, we need to better understand the 
contextual factors surrounding harm reduction practices and to ascertain whether these practices consist of finalized strategies used as alternatives to using condoms. This will require qualitative approaches with a thorough appraisal of the context and the meaning of the use of these practices or strategies. Regarding prevention, it is necessary to acknowledge the most commonly used risk reduction practices among MSM who do not systematically use condoms, and to address these practices in prevention activities in a balanced way, which represents a communication challenge (Hart \& Elford, 2010). It is important to stress that highlighting these practices is not equivalent to promoting them. MSM need accurate knowledge about the conditions under which these practices might actually reduce the risk of HIV transmission.

In particular, risks related to serosorting must to be properly addressed since a high incidence of acute infection could dangerously alter its efficacy. MSM need to be informed that acute infections may increase the HIV transmission rate, and that frequent HIV testing in high risk populations is important.

\section{Limitations and Strengths}

As part of the Swiss Behavioral Surveillance System initiated in 1987, the survey used in this study was based on a non-probabilistic sample. This approach allows for national coverage at a reduced cost. This does not allow us to infer our results to the whole MSM population in Switzerland. However, the broad dissemination of our questionnaire permitted us to attenuate selection bias and the use of the Internet allowed us to reach younger and less educated participants. One can expect, however, that this method could overestimate the level of risky behavior since several of the sites or newspapers used for recruitment were used for contacting partners.

Currently, many studies use different approaches to address risk reduction practices in MSM. However, most of the studies were limited to triangulating behavioral observations without inquiring about the intentional character of the harm reduction practices (Golden et al., 2008; Mao et al., 2006; Richters et al., 2000; Truong et al., 2006). Other studies investigated risk reduction practices by analyzing risk representations (Eaton et al., 2007; Gold \& Skinner, 2001). Our approach permitted us to estimate the prevalence of intentional harm reduction practices, but was still insufficient to ascertain whether these practices were used consistently or impulsively, or to understand MSM's beliefs concerning their level of protection. Qualitative studies are needed to further explore these practices and their importance in terms of individual risk management.

Acknowledgments Warm thanks to the participants, who responded to the survey as well as the associations, establishments, websites, and magazines that distributed the questionnaire. The authors have no conflicts of interest to report. This study was financed by the Swiss Federal Office of Public Health, Bern, Switzerland.

\section{References}

Balthasar, H., Jeannin, A., \& Dubois-Arber, F. (2005). Augmentation des expositions au risque d'infection par le VIH chez les hommes ayant des rapports sexuels avec des hommes: Premiers résultats de GAYSURVEY 04 [Increase in HIV risk exposure among men who have sex with men: Preliminary results from the GAYSURVEY 04]. Bulletin de l'Office Fédéral de la SantéPublique, 48, 891-895.

Balthasar, H., Jeannin, A., \& Dubois-Arber, F. (2007). Surveillance of HIV/AIDS-related behaviors among men who have sex with men: Switzerland, 1992-2004. International Journal of Public Health, $52,27-38$.

Balthasar, H., Jeannin, A., \& Dubois-Arber, F. (2008). Les comportements face au VIH/sida des hommes qui ont des rapports sexuels avec des hommes: résultats de Gaysurvey 2007 (Vol. Raisons de santé, 140). Lausanne: Institut universitaire de médecine sociale et préventive

Balthasar, H., Jeannin, A., \& Dubois-Arber, F. (2009). First anal intercourse among men who have sex with men in Switzerland. Archives of Sexual Behavior, 38, 1000-1008.

Balthasar, H., Jeannin, A., Lociciro, S., \& Dubois-Arber, F. (2010). Intentional risk reduction practices of men in Switzerland who have anal intercourse with casual male partners. Journal of Acquired Immune Deficiency Syndromes, 54, 542-547.

Berry, M., Raymond, H. F., Kellogg, T., \& McFarland, W. (2008). The Internet, HIV serosorting and transmission risk among men who have sex with men, San Francisco. AIDS, 22, 787-789.

Bezemer, D., de Wolf, F., Boerlijst, M. C., van Sighem, A., Hollingsworth, T. D., Prins, M., ... Fraser, C. (2008). A resurgent HIV-1 epidemic among men who have sex with men in the era of potent antiretroviral therapy. AIDS, 22, 1071-1077.

Bochow, M., Wright, M. T., \& Lange, M. (2004). Schwule Männer und AIDS: Risikomanagement in Zeiten der sozialen Normalisierung einer Infektionskrankheit. Eine Befragung im Auftrag der Bundeszentrale für gesundheitliche Aufklärung, Köln. Berlin: Deutsche Aids-Hilfe e.V.

Butler, D. M., \& Smith, D. M. (2007). Serosorting can potentially increase HIV transmissions. AIDS, 21, 1218-1220.

Crepaz, N., Marks, G., Liau, A., Mullins, M. M., Aupont, L. W., Marshall, K. J., ... Team, H. A. P. R. S. (2009). Prevalence of unprotected anal intercourse among HIV-diagnosed MSM in the United States: A meta-analysis. AIDS, 23, 1617-1629.

Dubois-Arber, F., Jeannin, A., \& Meystre-Agustoni, G. (2006). Un système de surveillance de deuxième génération pour améliorer la surveillance du VIH/sida en Suisse. Bulletin de l'Office Fédéral de la Santé Publique, 15, 277-281.

Dubois-Arber, F., Jeannin, A., \& Spencer, B. (1999). Long term global evaluation of a national AIDS prevention strategy: The case of Switzerland. AIDS, 13, 2571-2582.

Eaton, L. A., Kalichman, S. C., Cain, D. N., Cherry, C., Stearns, H. L., Amaral, C. M., ... Pope, H. L. (2007). Serosorting sexual partners and risk for HIV among men who have sex with men. American Journal of Preventive Medicine, 33, 479-485.

Eaton, L. A., Kalichman, S. C., O’Connell, D. A., \& Karchner, W. D. (2009). A strategy for selecting sexual partners believed to pose little/no risks for HIV: Serosorting and its implications for HIV transmission. AIDS Care, 21, 1279-1288.

Elford, J. (2006). Changing patterns of sexual behaviour in the era of highly active antiretroviral therapy. Current Opinion in Infectious Diseases, 19, 26-32.

European Centre for Disease Prevention and Control. (2009). HIV, AIDS surveillance in Europe 2008. Stockholm: European Center for Disease Prevention and Control.

Gold, R. S., \& Skinner, M. J. (1997). Unprotected anal intercourse in gay men: The resolution to withdraw before ejaculating. Psychological Reports, 81, 496-498. 
Gold, R. S., \& Skinner, M. J. (2001). Gay men's estimates of the likelihood of HIV transmission in sexual behaviours. International Journal of STD and AIDS, 12, 245-255.

Golden, M. R., Stekler, J., Hughes, J. P., \& Wood, R. W. (2008). HIV serosorting in men who have sex with men: Is it safe? Journal of Acquired Immune Deficiency Syndromes, 49, 212-218.

Halkitis, P. N., Moeller, R. W., \& Pollock, J. A. (2008). Sexual practices of gay, bisexual, and other nonidentified MSM attending New York City gyms: Patterns of serosorting, strategic positioning, and context selection. Journal of Sex Research, 45, 253-261.

Hamers, F. F., \& Downs, A. M. (2004). The changing face of the HIV epidemic in Western Europe: What are the implications for public health policies? Lancet, 364, 83-94.

Hart, G. J., \& Elford, J. (2010). Sexual risk behaviour of men who have sex with men: Emerging patterns and new challenges. Current Opinion in Infectious Diseases, 23, 39-44.

Ilaria, G., Jacobs, J. L., Polsky, B., Koll, B., Baron, P., MacLow, C., ... Schlegel, P. N. (1992). Detection of HIV-1 DNA sequences in preejaculatory fluid. Lancet, 340, 1469.

Jin, F., Crawford, J., Prestage, G. P., Zablotska, I., Imrie, J., Kippax, S. C., ... Grulich, A. E. (2009). Unprotected anal intercourse, risk reduction behaviours, and subsequent HIV infection in a cohort of homosexual men. AIDS, 23, 243-252.

Jin, F., Jansson, J., Law, M., Prestage, G. P., Zablotska, I., Imrie, J. C., ... Wilson, D. P. (2010). Per-contact probability of HIV transmission in homosexual men in Sydney in the era of HAART. AIDS, 24, 907-913.

Mao, L., Crawford, J. M., Hospers, H. J., Prestage, G. P., Grulich, A. E., Kaldor, J. M., \& Kippax, S. C. (2006). "Serosorting" in casual anal sex of HIV-negative gay men is noteworthy and is increasing in Sydney, Australia. AIDS, 20, 1204-1206.

Parsons, J. T., Schrimshaw, E. W., Wolitski, R. J., Halkitis, P. N., Purcell, D. W., Hoff, C. C., \& Gomez, C. A. (2005). Sexual harm reduction practices of HIV-seropositive gay and bisexual men: Serosorting, strategic positioning, and withdrawal before ejaculation. AIDS, 19(Suppl 1), S13-S25.

Pinkerton, S. D. (2008). Acute HIV infection increases the dangers of serosorting. American Journal of Preventive Medicine, 35, 184.

Pudney, J., Oneta, M., Mayer, K., Seage, G., \& Anderson, D. (1992). Pre-ejaculatory fluid as potential vector for sexual transmission of HIV-1. Lancet, 340, 1470.

Richters, J., Knox, S., Crawford, J., \& Kippax, S. (2000). Condom use and 'withdrawal': Exploring gay men's practice of anal intercourse. International Journal of STD and AIDS, 11, 96-104.

Snowden, J. M., Raymond, H. F., \& McFarland, W. (2009). Prevalence of seroadaptive behaviours of men who have sex with men, San Francisco, 2004. Sexually Transmitted Infections, 85, 469-476.

Steward, W. T., Remien, R. H., Higgins, J. A., Pinkerton, S. D., Sikkema, K. J., Truong, H. H., ... Morin, S. F. (2009). Behavior change following diagnosis with acute/early HIV infection-a move to serosorting with other HIV-infected individuals. The NIMH Multisite Acute HIV Infection Study: III. AIDS \& Behavior, 13, 1054-1060.

Suarez, T. P., Kelly, J. A., Pinkerton, S. D., Stevenson, Y. L., Hayat, M., Smith, M. D., \& Ertl, T. (2001). Influence of a partner's HIV serostatus, use of highly active antiretroviral therapy, and viral load on perceptions of sexual risk behavior in a community sample of men who have sex with men. Journal of Acquired Immune Deficiency Syndromes, 28, 471-477.

Sznitman, S. R., Romer, D., Brown, L. K., DiClemente, R. J., Valois, R. F., Vanable, P. A., ... Stanton, B. (2009). Prevalence, correlates, and sexually transmitted infection risk related to coitus interruptus among African-American adolescents. Sexually Transmitted Diseases, 36, 218-220.

Truong, H. M., Kellogg, T., Klausner, J. D., Katz, M. H., Dilley, J., Knapper, K., ... McFarland, W. (2006). Increases in sexually transmitted infections and sexual risk behaviour without a concurrent increase in HIV incidence among men who have sex with men in San Francisco: A suggestion of HIV serosorting? Sexually Transmitted Infections, 82, 461-466.

Trussell, J., \& Vaughan, B. (1999). Contraceptive failure, method-related discontinuation and resumption of use: Results from the 1995 National Survey of Family Growth. Family Planning Perspectives, $31,64-72,93$.

Van de Ven, P., Kippax, S., Crawford, J., Rawstorne, P., Prestage, G., Grulich, A., \& Murphy, D. (2002). In a minority of gay men, sexual risk practice indicates strategic positioning for perceived risk reduction rather than unbridled sex. AIDS Care, 14, 471-480.

Van de Ven, P., Murphy, D., Hull, P., Prestage, G., Batrouney, C., \& Kippax, S. (2004). Risk management and harm reduction among gay men in Sydney. Critical Public Health, 14, 361-376.

Van Kesteren, N. M., Hospers, H. J., \& Kok, G. (2007). Sexual risk behavior among HIV-positive men who have sex with men: A literature review. Patient Education and Counseling, 65, 5-20.

Velter, A., Bouyssou-Michel, A., Arnaud, A., \& Semaille, C. (2009). Do men who have sex with men use serosorting with casual partners in France? Results of a nationwide survey (ANRS-EN17-Presse Gay 2004). Euro surveillance: Bulletin européen sur les maladies transmissibles, 14.

Velter, A., Bouyssou-Michel, A., de Busscher, P.-O., Jauffret-Roustide, M., \& Semaille, C. (2007). Enquête presse gay 2004: Rapport. Saint-Maurice: Institut de Veille Sanitaire (InVS), Agence nationale de recherche sur le sida (ANRS).

Vittinghoff, E., Douglas, J., Judson, F., McKirnan, D., MacQueen, K., \& Buchbinder, S. P. (1999). Per-contact risk of human immunodeficiency virus transmission between male sexual partners. American Journal of Epidemiology, 150, 306-311.

Vittinghoff, E., \& Padian, N. S. (1996). Attributable risk of exposures associated with sexually transmitted disease. Journal of Infectious Diseases, 174(Suppl 2), S182-S187.

Wilson, D. P., Regan, D. G., Heymer, K., Jin, F., Prestage, G. P., \& Grulich, A. E. (2010). Serosorting may increase the risk of HIV acquisition among men who have sex with men. Sexually Transmitted Diseases, 37, 13-17.

Wolitski, R. J., Parsons, J. T., \& Gomez, C. A. (2004). Prevention with HIV-seropositive men who have sex with men: Lessons from the Seropositive Urban Men's Study (SUMS) and the Seropositive Urban Men's Intervention Trial (SUMIT). Journal of Acquired Immune Deficiency Syndromes, 37(Suppl. 2), S101-S109. 